\title{
AC 2012-2985: EMPLOYING A PROGRAM/PROJECT MANAGEMENT METHODOLOGY TO DEFINE AND DIFFERENTIATE UNIVERSITY-WIDE ROLES AND RESPONSIBILITIES IN PROFESSIONAL STUDIES
}

\section{Dr. Mitchell L. Springer PMP, SPHR, Purdue University, West Lafayette}

\begin{abstract}
Mitchell Springer is an Associate Professor in technology leadership and innovation and currently serves as the Director of the Purdue University College of Technology, Academic Center for Professional Studies in Technology and Applied Research (ProSTAR) located in West Lafayette, Ind. He possesses more than 30 years of theoretical and industry-based practical experience from four disciplines: software engineering, systems engineering, program management, and human resources. He sits on many university and community boards and advisory committees. Springer is internationally recognized, has authored numerous books and articles, and lectured on software development methodologies, management practices, and program management. Springer received his bachelor's of science in computer science from Purdue University, his M.B.A. and doctorate in adult and community education with a cognate in executive development from Ball State University. He is certified as both a Project Management Professional (PMP) and a Senior Professional in Human Resources (SPHR).
\end{abstract}

\section{Mr. Mark T. Schuver, Purdue University, West Lafayette}

Mark Schuver is the Associate Director for the Center for Professional Studies in Technology and Applied Research (ProSTAR) in the College of Technology at Purdue University in West Lafayette, Ind. $\mathrm{He}$ is responsible for the development and administration of the Weekend Master's Degree programs, the Rolls-Royce Master's Degree programs, and the growth of Professional Education programs in the College of Technology. Prior to joining Purdue in 2002, Schuver was employed by Caterpillar, Inc., for 35 years with assignments in product design, research and development, supplier management, quality management, logistics management, and various leadership positions. He holds an associate's degree in drafting technology from North Iowa Area Community College (1967), a B.S. in business administration (1990), and M.S. in management (1992) from Indiana Wesleyan University. Schuver is a member of the American Society for Engineering Education and serves on the Executive Board of the Continuing Professional Development Division. He is also a member of College/Industry Partnerships, Engineering Technology, and Graduate Studies divisions of ASEE. Schuver is a member of the National Collaborative Task Force for Engineering Education Reform and is a Lifetime Certified Purchasing Manager with the Institute of Supply Management (formerly NAPM). 


\section{Employing a Program/Project Management Methodology to Define and Differentiate University-Wide Roles and Responsibilities in Professional Studies}

Professional fee-based studies, through a myriad of program offerings in multiple program and curriculum formats, have the potential to significantly enhance the financial position of a college or academic department through intentionally focusing on professional adult learners. Given this, colleges and universities have focused resources, both financial and otherwise, on the centralization of administrative organizations targeting those professional adult learners who would normally not have an opportunity to participate in traditional programs. To create the multitude of potential educational opportunities, professional program organizations are required to fully understand the strategic educational capabilities and thrusts of attendant academic departments. This understanding leads to regular and frequent discussions with the academic departments. During these many discussions with academic departments, providing signature area courses and curriculums for professional studies, it is not uncommon for our professional studies administrative organizations to have to defend overhead rates, identified as expenses against gross revenue.

This paper focuses on the program management methodology employed to fully define and differentiate the roles and responsibilities of a professional studies administrative organization as well as contrast the role of other university partners. In doing so, the unique role and related responsibilities of each organization will highlight the value-added contributions of each interfacing organization. This paper capitalizes on ten years of providing professional studies support to academic departments utilizing multiple program formats including distance learning, distance hybrid and on-site programs. Where distance hybrid are programs with both face-toface instruction and a distance component.

Program/project management is a discipline with a defined process, having multiple generally sequential activities, where each activity has an attendant product. The definition and subsequent differentiation of roles and responsibilities of the many interfacing administrative organizations for professional studies lends itself to the many activities of the program/project management process and the product depiction of the process activity outcomes.

Following the above process, the statement of work, stated and derived requirements, work breakdown structure and responsibility assignment matrix are designed, developed and seamlessly integrated into a planning template for subsequent execution. This paper will identify the process activities and products generated as applicable to defining and differentiating the roles and responsibilities of a professional studies organization within the construct of a university-wide system of interfacing support administrative bodies.

The process activities of program and project management - 
Program and project management as a process has multiple activities. A simple perspective asks a number of questions, around which are processes to further define the specific instantiation of the application of the program management methodology. In this scenario, program and project management has been used as a tool to define a research-based tier 1 university's organization for professional studies.

In defining the roles and responsibilities, the basic work definition questions to be addressed following a program management process are ${ }^{1}$ :

- What is the target organization being asked to do?

- What work is there to be done?

․ Who will be performing the work?

While there are numerous other related questions to further defining an executable program plan, the initial definition of the work is most critical to subsequent activities.

What is the professional studies organization being asked to do?

Successfully defining the work to be performed requires an analysis of the request for work to be performed, most generally referred to as a request for proposal, or in the case of our target professional studies organization, the mission statement. The mission statement for the Purdue University Center for Professional Studies in Technology and Applied Research (ProSTAR) reads as follows ${ }^{2}$ :

The ProSTAR mission is to provide education, and, engagement in applied research, for business and industry.

a To provide fully accredited degrees, certificates, courses, and workshops to professionals in industry at the local, state, regional, national and international levels

a To actively pursue the scholarship of Professional/Technology Education

a To actively pursue industry-based engagement in applied research through the College of Technology.

\ To deliver programs on campus, by distance, on site, or a combination utilizing applicable industry-specific education mediums.

This mission, then, provides the framework for identifying the stated and derived requirements for the work to be performed.

What work is there to be done?

Work to be performed may be defined as "stated" and "derived" requirements" ${ }^{3,4}$. A stated requirement is one stated directly and explicitly in the provided mission statement. In this scenario, the stated requirements, although many, may be defined generally as:

\ Provide accredited degrees 
- Provide certificates

- Provide workshops

- Service populations at the local, state, national and international level

- Provide industry engagement through applied research

\. Deliver programs by distance, on-site or a combination of education mediums

While the stated requirements provide the explicit desires as stated in the mission statement, the derived requirements are those things that must be done to satisfy the stated requirements. Derived requirements are those requirements not explicitly stated but deemed necessary to fully satisfy the stated requirements. The derived requirements could be nearly infinite. It is only necessary to identify those high-level derived requirements that pose significant cost, schedule or performance implications. In this scenario, derived requirements may be defined as:

- Accredited degrees are defined as Bachelor or Masters degrees

- Accredited degrees are credit-based versus non-credit certificate courses

- Certificates may be defined as either credit or non-credit certificates

- Workshops may be defined as non-credit courses

- Business office support is required

- Marketing support is required

a Applied research is required

Again, while there may be literally hundreds or even thousands of derived requirements, only those at the highest level need to be defined; those that are cost, schedule or performance drivers.

The management of the process used to evolve the requirements of the effort is referred to as requirements management. As a process, requirements management has five basic steps:

口 Identification

- Analysis

- Allocation

口 Verification

口 Traceability

Identification is the process of collecting both stated and derived requirements as reflected above. Analysis is the step of the requirements management process that separates similar requirements into chunks or groupings of higher-level requirements. Allocation is the process step that allocates the requirements to an individual or organization to perform the work and subsequently satisfy the identified requirements, either stated or derived. Verification is the process step of determining how well the identified requirements were satisfied. There are generally four basic types of verification: analysis, inspection, demonstration or test. Each of these types of verification has cost and schedule implications. Traceability is the process step of 
tracing the stated or derived requirement through the evolution of the target instantiation and therefore ensuring it has been addressed and subsequently satisfied or not.

Once work has been sufficiently identified, it is then depicted in a work breakdown structure (WBS). The WBS for our target professional studies organization may resemble the below figure 1.0.

Figure 1.0 Professional Studies Work Breakdown Structure -
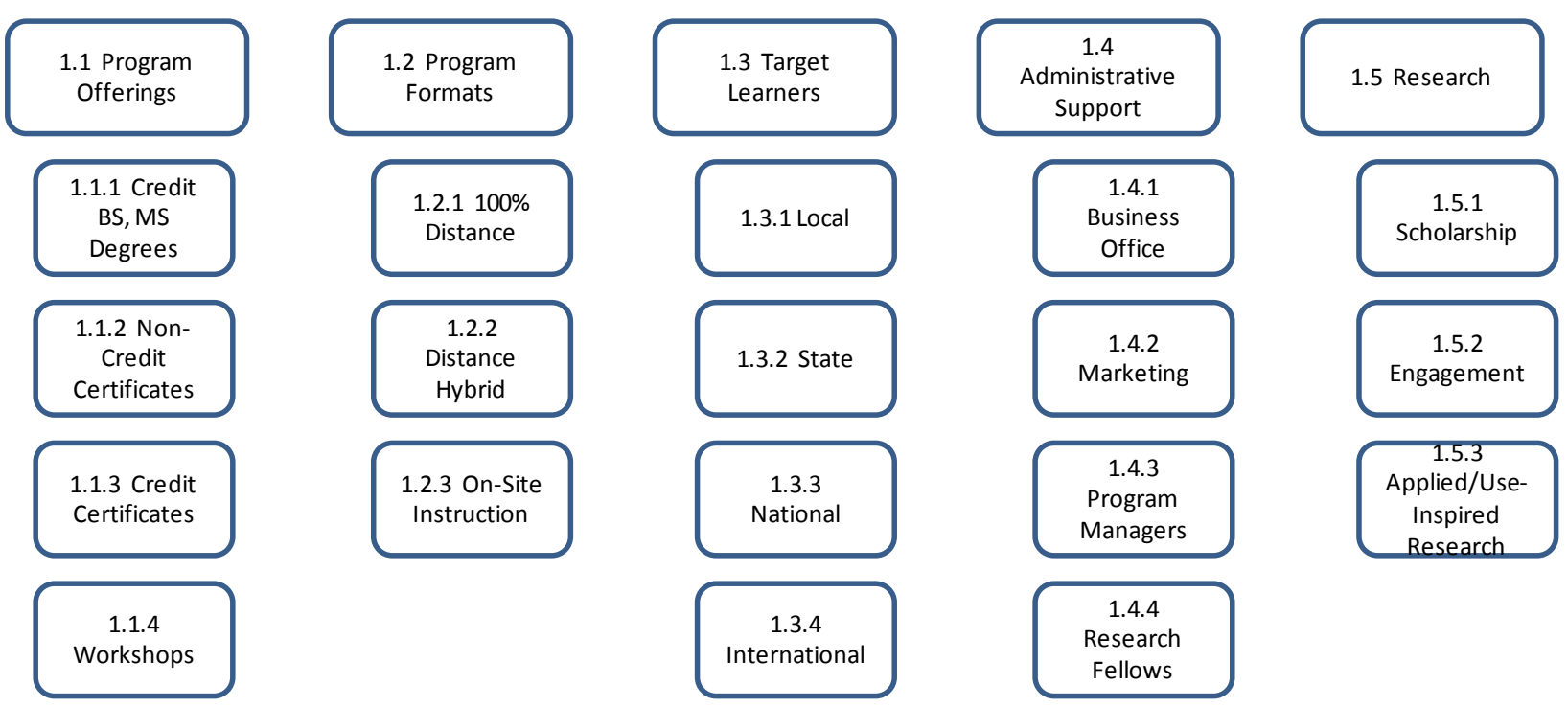

Worth noting is that there is no right or wrong WBS structure, only more or less applicable. The WBS should map to the manner in which the conceived organization is prepared to execute the work. To this end, an alternative WBS structure may have been equally correct if organized by functions performing the work; Program Managers, Research Fellows and others as appropriate. The determination as to which WBS structure is the most applicable is the one most aligned to how the target organization is organized to perform the work.

Who will be performing the work?

Once the work is organized into a logical collection of related tasks, the next activity of the program and project management process is to assign the work to functional organizations, or individuals, who will be performing the work. This end product is referred to as a Responsibility Assignment Matrix (RAM). 
To simplify the transition from the WBS to the RAM, it is assumed there are levels of detail in the WBS not currently reflected in the above. Given this, the below is a depiction of the mapping of work to be performed (WBS) to the individual/organizations responsible for performing the work. The field identified as the Primary Areas of Responsibility should list all of the work reflected in the WBS. No work in the WBS should go without being depicted in the RAM.

Figure 2.0 Responsibility Assignment Matrix (RAM)

\begin{tabular}{|c|c|c|c|c|c|c|}
\hline \multicolumn{7}{|c|}{ Professional Studies Organization } \\
\hline Primary Areas of Responsibility & Director & $\begin{array}{c}\text { Associate } \\
\text { Director }\end{array}$ & $\begin{array}{c}\text { Program } \\
\text { Manager } \\
\text { (1) }\end{array}$ & $\begin{array}{l}\text { Program } \\
\text { Manager } \\
\text { (2) }\end{array}$ & \begin{tabular}{|c|} 
Office \\
Manager/ \\
Event \\
Planner
\end{tabular} & $\begin{array}{c}\text { Research } \\
\text { Fellow }\end{array}$ \\
\hline Departmental Responsibility & $\mathbf{P}$ & $\mathbf{S}$ & & & & \\
\hline Budget Responsibility & $\mathbf{P}$ & $\mathbf{S}$ & & & & \\
\hline Liaison with Outside Interests & $\mathbf{P}$ & $\mathbf{S}$ & & & & \\
\hline Research Administration & $\mathbf{S}$ & & & & & $\mathbf{P}$ \\
\hline Graduate Program Conceptualization & $\mathbf{P}$ & $\mathbf{S}$ & & & & \\
\hline Graduate Program Concept Development & & $\mathbf{P}$ & $\mathbf{S}$ & $\mathbf{S}$ & & \\
\hline Distance Hybrid Program Development & & $\mathbf{S}$ & $\mathbf{P}$ & $\mathbf{S}$ & & \\
\hline PhD Program & $\mathbf{P}$ & $\mathbf{S}$ & & & & \\
\hline Distance Learning & $\mathbf{P}$ & & $\mathbf{S}$ & & & \\
\hline Distance Learning Programs & & & $\mathbf{P}$ & $\mathbf{S}$ & & \\
\hline Non-Credit Open Enrollment Offerings & & & $\mathbf{S}$ & $\mathbf{P}$ & & \\
\hline Certificate Credit Programs & & & $\mathbf{S}$ & $\mathbf{P}$ & & \\
\hline Industry Partnerships & & $\mathbf{P}$ & $\mathbf{S}$ & $\mathbf{S}$ & & \\
\hline International Programs & & & $\mathbf{P}$ & $\mathbf{S}$ & & \\
\hline $\begin{array}{l}\text { Strategic Initiatives (Executive Advisory } \\
\text { Board, Newsletter creation and maintenance, } \\
\text { etc.) }\end{array}$ & & $\mathbf{P}$ & $\mathbf{S}$ & $\mathbf{s}$ & & \\
\hline Office Management & & & & & $\mathbf{P}$ & \\
\hline Event Planner & & & $\mathbf{S}$ & $\mathbf{S}$ & $\mathbf{P}$ & \\
\hline Student Liaison & & & $\mathbf{S}$ & $\mathbf{S}$ & $\mathbf{P}$ & \\
\hline Process Management & & & $\mathbf{P}$ & & $\mathbf{S}$ & \\
\hline Website Management & & & $\mathbf{P}$ & $\mathbf{S}$ & $\mathbf{S}$ & \\
\hline Project Coordination & & & $\mathbf{S}$ & $\mathbf{S}$ & $\mathbf{P}$ & \\
\hline Program(s) Accreditation & & $\mathbf{P}$ & & $\mathbf{S}$ & & \\
\hline ASEE Program Board Affiliation & $\mathbf{S}$ & $\mathbf{P}$ & & & & \\
\hline \multicolumn{7}{|l|}{$\mathrm{P}=$ Primary Responsibility } \\
\hline$S=$ Secondary Responsibility & & & & & & \\
\hline
\end{tabular}

In this scenario, the primary and secondary responsibility is mapped to the performing organization/individual. If the budget per WBS element was known, then the "P" and "S" 
nomenclature would have been replaced by the actual budget allocated to the identified work. In defining the work for a professional studies organization, however, it is the work to be performed more than the cost of the work that is important. The exception to this might reside in budgets allocated to marketing activity or similarly identified work with budget implications.

The RAM reflects primary responsibility for the activity or event. Others may very well be involved in executing the defined work through delegation or collaboration.

The final product of the requirements definition phase of the program and project management process is the organizational chart. The organizational chart may be depicted by function, made up of logical groupings of work, or, by individual assigned to perform the identified work. Below is an organization chart depicted by individual responsible for performing the identified work $^{5}$.

Figure 3.0 Organization chart by individual

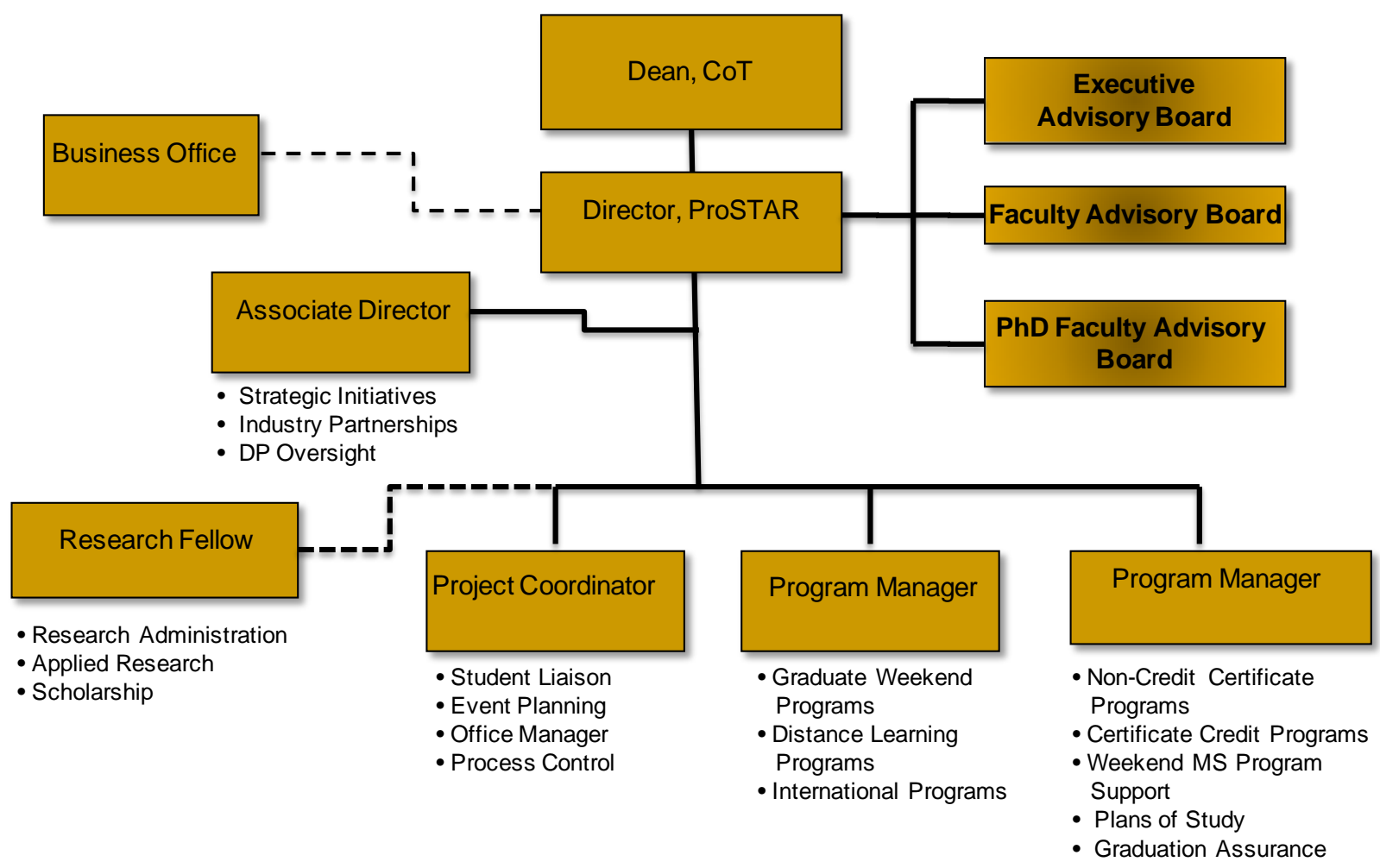

The organizational chart could have been organized by work to be performed versus by individual. This depiction is reflected in figure 4.0 below.

Figure 4.0 Organization Chart by work to be performed 


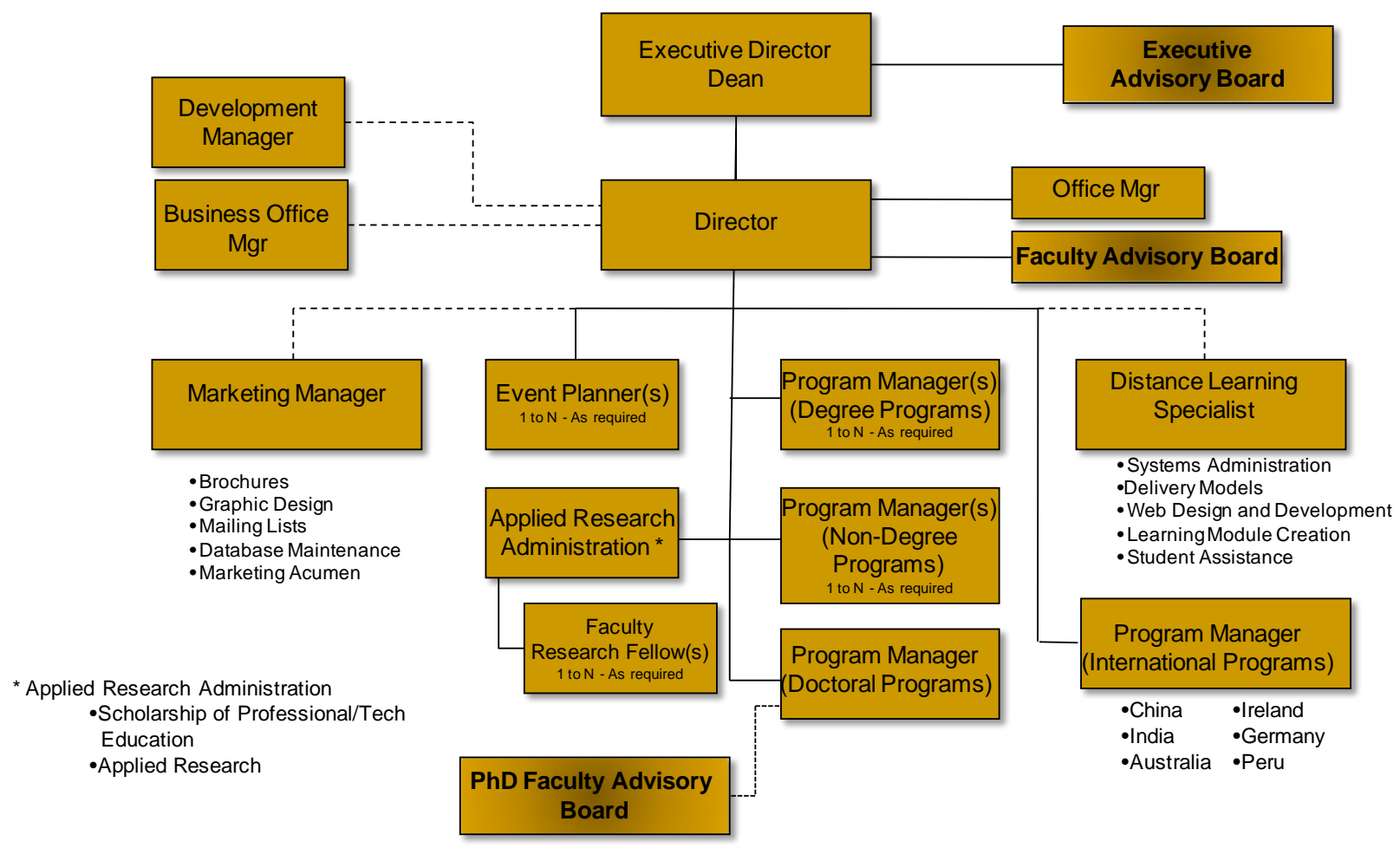

Once the work to be performed has been defined, it not only becomes clearer what work the professional studies organization has responsibilities for, but equally, which organizations are involved in performing the work tangential to the professional studies organization. In this scenario there were six separate yet highly interrelated organizations; the academic department, college business office, Dean of Graduate Studies, Purdue Extended Campus (PEC), university Graduate School and ProSTAR. The primary role of each of the organizations is depicted below.

๑ Academic Department

- Signature area expertise

- Faculty assignment/development/compensation

- Target market contacts for signature area

- Curriculum development

a College Business Office

- Budget development and oversight

- Faculty compensation oversight

- New program pro forma creation

- Dean of Graduate Studies

- College level graduate program oversight

- Policy development and interpretation

- Probation/Dismissal oversight

- Liaison with university graduate school

- Applicant acceptance oversight 
口 Purdue Extended Campus (PEC)

- Fee collection and fund disbursement

- Student registration

- Prime interface with bursar, financial aid and registrar

- Rate request for program oversight

- CEU management for certificates

a Graduate School

- Overall policy development and oversight for graduate programs

- Incoming student acceptance processes

- Determination of graduation eligibility

- Graduate faculty appointment process

- New program approval coordination

口 ProSTAR

- Main interface with academic departments

- Marketing coordination

- Recruiting process

- Business office interface

- Purdue extended campus interface

- Event planning and execution

- Distance education technology and implementation

- Collaboration with other colleges

\section{Conclusion}

The program and project management process is a process with multiple semi-sequential activities where each activity has an attendant product. The process may be used to plan programs for highly-sophisticated asynchronous geo-spatial satellite systems, planting a garden or anything in between. Everything we do begins with an identification of the requirements. Program and project management has been around in an informal, inconsistent and undocumented form since the beginning of time. Understanding that a process does exist provides an opportunity to follow a logical and sequential methodology for defining all that we do. In this paper we described the successful use of a program and project management process as a tool in defining the instantiation of work and organization for a professional studies organization. This process also provided insight into work attendant to tangential organizations to the administrative organization of this paper.

Feedback from peripheral organizations reflects the success of the organizational model currently in place. Experience suggests having a clearly defined organizational structure as well as succinctly differentiated roles and responsibilities provides for a more efficient overall university-level interfacing structure. 


\section{Bibliography}

1 Springer, M. L. (2010). Project and program management: A competency-based approach. West Lafayette, IN: Purdue University Press.

2 Bertoline, G., \& Schuver, M. (2009). The Center for Professional Studies in Technology. ASEE 2009 Annual Conference Proceedings. Austin, TX.

3 Kerzner, H. (2009). Project Management: A Systems Approach to Planning, Scheduling and Controlling. Hoboken, NJ: John Wiley \& Sons.

4 Cleland, D. (1994). Project Management: Strategic Design and Implementation. New York, NY: McGraw-Hill Inc.

5 Springer, M. L., Bertoline, G. R., \& Schuver, M. T. (2011). Building an academic center infrastructure for professional development. ASEE 2011 Annual Conference Proceedings. Vancouver, B.C. 